\title{
SOLVING PROBLEMS OF PRACTICE TO BROADEN PARTICIPATION IN CYBERSECURITY EDUCATION
}

\author{
Debra A. Nakama, University of Hawaii Maui College, debran@hawaii.edu \\ Karen Paullet, Robert Morris University,paullet@rmu.edu
}

\begin{abstract}
Educational technologies have taken on increasing importance as it continues to grow and provide amazing opportunities to students in rural communities. Moreover, with the steady development of online education and online learning environments, expanding cybersecurity educational pathways in rural communities is conceivable. This paper outlines a case study that uses an online technology to explore: How to increase the number of women and minority high school students in cybersecurity?

The study used the maturation of information and communication technologies to eliminate the barriers faced by underrepresented students in rural communities and fostering their untapped talent for the advancement of the nation's cybersecurity workforce. The results of this study revealed, information systems and technology support elearning and build cybersecurity knowledge while broadening participation for women and minority high school students in rural communities. Moreover, this study highlights the importance of ongoing improvement interventions to advance the impact that online educational technologies can have on broadening participation in rural communities.
\end{abstract}

Keywords: Information Technology, E-Learning, Cybersecurity Educational Pathways, High School-University Collaboration, Early College, and Broadening Participation

\section{INTRODUCTION}

Challenge Minorities, Women and Cybersecurity Education. With the growing demand for cybersecurity technicians increasing, and few programs available for training, supply of competent technicians is low (IBM, 2013). This is compounded by the under representation of minorities and women in IT fields (Chai, Bagchi-Sen, Goel, Rao \& Upadhyaya, 2006). Meanwhile, minorities are also the most rapidly growing segment in the general population (Margolis, J., et. al., 2008). Women hold 56\% of all professional jobs in the U.S. workforce, but only $25 \%$ of IT jobs (NCWIT, 2013). Moreover, only $13 \%$ of U.S. cybersecurity professionals are women (IDC, 2012). Meeting the growing demand for cybersecurity technicians begins in the education system. The need for a curriculum on cybersecurity is critical to the success of tomorrow's business leaders.

The trends, challenges, and leading practices show that cybersecurity education programs are entering a period of transformation (IBM, 2013). Despite the progress being made, educational institutions need to do more to fully embed cybersecurity practices and principles into academic programs and across educational sectors and address the need to build students' interest in STEM related fields at multiple levels along the pipeline, from high school to the professoriate (Syed \& Chemers, 2011). Cybersecurity training is embedded in the broader issue of STEM education and challenges. But while the number of STEM degrees awarded from 2004 to 2009 increased, those in computer science decreased sharply. Representation of women and minorities receiving computer science degrees is even lower.

While women earn $57 \%$ of all bachelor's degrees, and half of all science and engineering bachelor's degrees since the 1990's, the percentage of women earning computer science degrees is only $18 \%$. For minority women, those numbers drop into the single digits.

More depressing, the decline in the number of first-year undergraduate women interested in majoring in computer science has declined $79 \%$ in the last 10 years, from 2000 to 2011 (all from the U.S. Department 
of Labor, Bureau of Labor Statistics, 2011). Looking at recent Advanced Placement statistics, in which only $19 \%$ of the computer science test takers were women, the situation is unlikely to change soon (Computing in the Core, 2012).

The National Initiative for Cybersecurity Education (NICE) in concert with key stakeholders encourages educational sectors to make the necessary connections between cybersecurity and the STEM skills our cybersecurity workforce needs to ensure a more secure cyberspace (NICE, 2012). Many popular and wellestablished stakeholder partnerships have established high school cybersecurity competitions in a variety of settings. While these events are exciting and important as contests of skill, participations require considerable a priori domain knowledge and practical computer security expertise. Therefore, the average high school student may be excluded from taking part in these events or may not fare well in the actual competition and be discouraged to future efforts.

High School-University Collaboration. The community college connection to high schools is widely increasing via a number of models that offers early college options (Morest, V. S. and Karp, M. M., 2006; Bragg, D., 2013). In addition, community colleges are central to focusing on this new wave of America's high school women and minorities in these initiatives to improve their labor market prospects (Osterman, P., 2012). This three-year study highlights a high school-university collaboration involving all Maui County high schools and the University of Hawaii Maui College (UHMC) in introducing a new cybersecurity educational pathway. UHMC is a rural hybrid community college that offers three (3) Bachelors of Applied Science Degrees. One of the degrees is a Bachelors of Applied Science Degree in Applied Business Information and Technology (ABIT), with a certification in cybersecurity to seven high schools.

Cybersecurity educational pathways for high school students are at its infancy in Hawaii's rural communities. This project offered a new college level cybersecurity educational pathway to high school students via a supportive online learning environment. This study was funded by the National Science Foundation (NSF) Scholarship for Service (SFS) [Award \#1516178 (10/15/2015-09/30/2017)]. This three-year study is designed to increase the number of minorities and young women succeeding in college level cybersecurity education and degree programs by offering a Cybersecurity Certificate of Competence [four (4) courses]. The following is the listing of the Information Computer Science (ICS) courses and its description for the Cybersecurity Security Certificate of Competency.

ICS 101 - Digital Tools for the Information World - Emphasizes production of professional level documents, spreadsheets, presentations, databases, and web pages for problem solving. The course includes concepts, terminology, and a contemporary operation system.

ICS 169 - Introduction to Information Security - Prereq: ICS 101 with grade C or better, or consent. This course provides the basic foundation to information security, including identifying threats, planning for business continuity, and preparing for various security attacks. Focus will be given to threats to financial security such as attacks on banking and other related financial information. Special emphasis on ethics and legal issues that covers hacking and other cybersecurity techniques and tactics.

OR

ICS 110 - Introduction to Computer Programming - Prereq: ICS 101 with grade C or better, or consent. Teaches fundamental programming concepts including sequential, selection, and repetition flow; variables and types; syntax; error types; compilation; linking; loading; and debugging. Introductions algorithms flow charts, UMI, and other analytic tools. Explains and practices problem solving and critical thinking methods.

ICS 184 - Introduction to Networking - Prereq: ICS 101 with grade C or better, or consent. Provides the student with the knowledge and skills to manage, maintain, troubleshoot, install, operate and configure basic network infrastructure, as well as to describe networking technologies, basic design principles, and adhere to wiring standards and use testing tools. 
ICS 171 - Introduction to Computer Security - Prereq: ICS 101 or consent. Examines the essentials of computer security, including risk management, the use of encryption, activity monitoring, intrusion detection; and the creation and implementation of security policies and procedures to aid in security administration.

Early college access is complex with multiple causal and mediating factors that govern access for different groups and individuals. Sargut and Mcgrath (2011) state there are three properties that determine the complexity of an environment: (1) multiplicity refers to the number of potentially interacting elements; (2) interdependence, relates to how connected those elements are; and (3) diversity, has to do with the degree of heterogeneity.

Educators assume that students enrolled in online learning are geographically dispersed, that they learn at different times and that visual contact is limited or does not exist (Dabbagh, 2007; Kear, 2010). In such environment, teachers have limited possibilities to determine the level of students' engagement, thus, not being able to focus on a particular student (or group of students) in order to increase the level of engagement.

Historical roots of bureaucratic management of high schools and higher education create a strong legacy and entrenched perspective on operations and structures of college access. This project views the early college cybersecurity educational pathway access and participation as an organic complex system that contains a large number of interactive, interdependent, diverse elements; moreover, the greater the multiplicity, interdependence, and diversity, the greater the complexity. The essential features may operate in patterned ways but their interactions continually change. In this paper, we highlight the importance of adopting ongoing interventions to advance the impact that online educational technologies can have on broadening the participation in rural communities. This study explored a problem of practice, a problem for which a remedy is urgently sought that can be locally implemented. Through an iterative research process, the study centered on how to deliver cybersecurity education to high school students who did not have access to any cybersecurity pathway of study.

\section{RESEARCH METHODOLOGY}

To provide Cybersecurity courses to more students, this project used a design-based implementation research (DBIR) that embraces a commitment to organizing and studying e-learning to promote coherence and equity and to help local actors engage in work of transformation through a collaborative, iterative, coordinated set of practices. The study's aim is not just to study how and when efforts to organize new forms of e-learning do work, but rather how to improve and make them work equitably under a wide range of conditions (Bryk, 2009).

DBIR is a hybrid form of action research methodology. Jean McNiff (2013) asserts that action research methodology is a powerful strategy to support democratic activity because it positions the nature, origin and uses of knowledge as central principles and practice to the transformation process. Moreover, McNiff (2013) claims that interface of the digital communication technologies and new research methodologies facilitate a fresh perspective that embraces the concept that knowledge resides in intuitive interactions.

Thus, the merging of DBIR, takes place as a real-life dialogical practice within real-life socio-political contexts where researchers as practitioners become engaged in knowledge creation with potential for personal, social and institutional transformation by building the capacities for social justice programmatic leadership via high schooluniversity collaboration. This study aligns with Bryk, Gomez, Brunow and LeMahieu (2016) improvement science design to facilitate learning and innovation throughout the project. The DBIR employed an iterative process that identified what the challenges were, and tracked the impacts on students' learning, motivation, and other desirable outcomes. Finally, this blended theoretical framework follows the critical social science or critical theory. Chai, Bagchi-Sen, Goel, Rao and Upadhyahya (2006) claim that underrepresentation of minority workforce in the IT industry is one of the reasons for the scarcity of skilled labors in the information security industry. To broaden participation in cybersecurity, the research centered upon the following research question: How to increase the number of women and minority high school students in cybersecurity? 
Interventions are designed consisting of a sequence of activities that pivot on outcomes (Mintrop, R., 2016). The aim is to distill some prototypical elements (activities, tools, learning principles) that are iteratively tried out, analyzed, and revised until an acceptable balance between ideals and reality has been achieved (Ibid.). The project focuses on equity-relevant designs that are not done to students but are developed with major stakeholders (students, counselors, industry, business) in a co-design dynamic. Interaction in a co-design team means creating a culture of dialogue that enable all members, regardless of status and role in the organization, to engage in the learning process.

According to Mintrop (2016), and utilized in this project, are the following qualities to make design development research-based.

1. Interventions consist of carefully planned tools, activities, or organizational formats that are hypothesized to elicit for foster the kind of student learning needed to achieve intended outcomes.

2. Trial and error in accomplishing outcomes is deliberate; it is undergirded by a theory of action drawn from the professional knowledge based. The theory's validity can be assessed by evidence that interventions activities generate.

3. Data are collected according to reliable procedures that document and evaluate the design implementation process and impact (p. 135).

\section{Case for Intervention \#1: Role of Project Insiders versus Outsiders}

Recruitment of Cohort One and Cohort Two. The project proposed to engage at least 72 underrepresented high school students with core topics in cybersecurity over two years. The First Cohort of students in Spring 2016 contained 41 students and in summer 2016 Cohort Two consisted of 43 new students. Thus, during Year One of the grant 84 students have already participated in the project. This surpasses the expectation for the entire two years of the grant. For both cohorts, females outnumbered males. The project for year one was evaluated by an external evaluator via online surveys, a site visit to the University of Hawaii Maui College (UHMC), interviews with PIs, follow up data on students, and attendance at the Advisory Board meeting.

The cohort did not adequately reflect the available population of Native Hawaiian/Part-Hawaiians. Therefore, the project explored ways to attract more Native Hawaiian/Part-Hawaiians to the cyber pathway. The project recruited through an Open House, which included parents and through a Senior Counselor. The project personnel went to private schools with a high percentage of Native Hawaiians. They were able to recruit eight students from two private schools.

An innovative strategy to reach Native Hawaiians/Part-Hawaiians was also used by this program. In addition to traditional STEM recruitment, they recruited students from the Arts and Communication pathway, a non-STEM pathway of study. As an "insider" versus an "outsider" to both institutions, the program increased their concentration of Native Hawaiians/Part-Hawaiians and served as a successful, innovative way to recruit students into cybersecurity. Thus, from Cohort One to Cohort Two the percentage of Native Hawaiians/Part-Hawaiians increased from $7 \%$ to $19 \%$.

\section{Case Intervention \#2: Learning Management System - Importance of On-line Navigation}

One of the obstacles for the successful implementation of the project has been the issue related to the Learning Management System (LMS) used. The high school students found it difficult to access the LMS, Sakai. This LMS is an open system used for higher education to address the needs of a global community (Sakai, 2018). Students were also required to use TestOut as a supplement to the LMS. TestOut is an outside LMS that provides labs for academic institutions allowing students to have hands-on experience to labs in a simulated environment (TestOut, 2017). In addition, there were compatibility issues between Test Out and Laulima, the Learning Management System used by UHMC. This created additional issues for the students and potentially may have increased the number of student withdrawals. Students from the first two cohorts who withdrew from the project were administered a survey. This allowed the project to identify problems to address for improvement.

From both cohorts the number one reason that students withdrew was related to time management issues (such as balancing AP classes, extracurricular activities, or simply procrastination). High school students struggled with balancing their high school classes, activities and home lift while completing college pathway classes. Students had 


\section{Issues in Information Systems \\ Volume 19, Issue 4, pp. 1-9, 2018}

to learn to dedicate time to the work taught via the LMS. However, students also identified a reason for their withdrawing from the project was related to the Learning Management System. Students did not have the proper training for utilizing the LMS. During the first few weeks of the class students had issues with understanding how to access the class, where to find the information once in the class and how to navigate while in the LMS.

From the first cohort of students who withdrew from the class one reported, "The way we did the work was time consuming because it would load slowly at times". Students had issues with the LMS loading content. Another student from this Cohort commented on the vague prompts from the system. The prompts need to be set by the instructor and taught to the students. Two students felt that there should have been more due dates throughout the course. Providing students with a structured set of assignments with due dates is imperative to the success of the course.

The second cohort of students who withdrew from the class reported similar issues. When students who withdrew from the class were asked why they withdrew, the majority of the students responded with issues related to time management. However, one student reported that they were confused as to whether they were enrolled in the class and another student reported compatibility issues with the Learning Management System. Another student reported, "Maybe the project could explain more and sometimes it was slightly confusing". An additional student stated that they would have been more successful in the class if, "More time and an easy way to get in the files". A student reported that their computer was not compatible with the system.

Even students who successfully completed the class reported that there were compatibility issues with the system and their computers. One student said that no matter what they did, "some keys just didn't work no matter what I tried".

Case Intervention \#3: Community of Presence and Engagement

The following section are samples of email communication that highlights the need to monitor students' presence within the community.

Emails from College Instructor to College Support Staff (Coach/Counselor)

James is holding an 18\%. He isn't even logging in. I can look at the diagnostics and see he has not been in the classroom or TestOut in weeks. Additionally, Sam is holding a 14\%. It is impossible for either of them to pass at this point. They are not even trying.

I am reaching out to let you know that the below students have yet to take Exam 1 which was due two weeks ago. During the exam week students were not given any other assignments.

If she is able to log in then she is able to see the assignments. The student must be clicking on the incorrect tabs to access the course material.

Emails from College Support Staff to Instructor (Coach/Counselor).

I am still following up on Tom with his high school counselor and vice principal. Tom is insisting on remaining in the class. However, he is doing very little work while at the same time he is failing some of his classes at his high school.

Thank you for the updates. I spoke with the student yesterday afternoon and she said she caught up with the Discussion assignments. Tennis season has started for her and she knows she has to work even harder on managing her time. Continue to keep me in the loop.

Spoke with high school counselor about her students. She has a call out to the students but hasn't make contact with the students as of this early afternoon. I will get back to you once she makes contact with the students.

Emails from Instructor to Students. 
I am reaching out to let you know that since you have completed Discussion 1, Discussion 2 and Discussion \#3 they have results in a zero grade for each assignment. The weekly assignments are listed in the Announcements, which are also sent out to the students each week along with follow-up reminders. Going forward please be sure to complete all work assigned both in TestOut and Laulima. If you have any questions, please do not hesitate to ask.

Emails from College Support Staff (Coach) to Students.

It has been called to my attention that you haven't taken the Exam 1 which will affect your grade for the course. I am encouraging you to get caught up with the class and please use the upcoming spring break to make up any work.

Emails from Students to both Instructor and College Support Staff (Coach).

I sincerely apologize for not taking the time to complete each section in its' entirety within TestOut. Though I'm taking 5 AP courses along with this course, I should have realized that I cannot simply complete the graded assignments without taking the time to learn the material through TestOuts videos and handouts. From now on, I will ensure to complete the previous sections in this entirety as well.

As indicated in the above set of email communications between the students, college support staff and instructors, it is clear to see that the students have trouble with time management, navigating the LMS and accessing the LMS as mentioned earlier. In order to help students, succeed, changes had to be made to the learning environment. The students enrolled in the early admit college project are from rural Hawaiian Islands. In most cases it is the students first time taking an online class and first-generation college students. To help improve the student's retention, supplemental items were needed. Faculty teaching the courses had to adjust their teaching styles on a class-by-class basis. For instance, to get students engaged, online teaching faculty had to make time to Skype with the class. This gave the students the opportunity to ask questions and understand the LMS, course requirements and expectations and how to navigate both Laulima and TestOut.

One-on-one phone calls were made to students struggling with the course content. The counselors would reach out to faculty if the students had questions to make sure that they were getting the answers. Faculty that teach online classes are not required to hold Skype or Google Hangout sessions, work with counselors on a daily basis and work one-on-one with individual students to steer them on the right path. This adjustment of faculty presence was needed to help students succeed. Faculty had to help motivate students to keep them on track throughout the class. Constant email communication and reminders were needed to help the students make it through the courses.

\section{SUMMARY/IMPLICATIONS FOR PRACTICE}

One of the biggest challenges for the high school students in the transition from high school to college is the change from a teacher-directed to a student-directed environment; rarely does a college instructor monitor students' progress (Dembo and Seli, 2013). In college, students are expected to manage their own learning (Bembenutty, 2011). Additionally, high school teachers spend considerable time attempting to motivate students to learn, whereas college instructors generally expect students to be self-motivated. An online course format intensifies the culture shock and difficulties for high school students' first early college experience.

Another important functioning set of skills in early college online course dynamics to overcome its contextual constraints are: (1) learning how to navigate the learning management system, and (2) sending and receiving messages effectively between students and faculty. Help seeking is essential prerequisites among online learning strategies because students may feel that it implies they are incapable of completing the academic tasks without assistance, which can be threatening to self-worth. As a result, many college students fail to seek needed help, considering it embarrassing, an admission of defeat, and something to be avoided whenever possible (Karabenick \& Dembo, 2011).

We are learning how to innovate promising cybersecurity educational pedagogies and support methodologies for 


\section{Issues in Information Systems \\ Volume 19, Issue 4, pp. 1-9, 2018}

early college high school students via an informative iterative process. Our iterative process has led us to explore deeper issues in innovation and the essential role of stakeholders across educational sectors.

Since the data features continually evolve via recent changes over 12 weeks, further feedback and reflection should be done to refine its improvements. Transferability refers to the extent that these findings can be applied to other populations, contexts, or individuals. A number of factors impact the application of these results to other groups, demographics and sample size. It is entirely possible that the results would be different if the research were conducted in another city or state, or if the research utilized a cross sample of locations within the United States. Sample size is another limitation of this study. Because of the resources and time, the number of participants was limited. Thus, consideration should be used when applying these results to studies of other cybersecurity early college project overall.

Practitioners in this study suggested that more study of online cybersecurity educational pathways are needed because there is a vacuum of opportunities afforded high school students in rural communities. However, there is a lack of research and practitioner's partnership collaborating to take advantage of the new possibilities that convergence of motivation and educational technology with early college affords institutions in broadening participation for rural communities.

\section{Future Studies}

Going forward it is important to keep in mind that the development of a reliable early online cybersecurity pathway for high students in rural communities is both desirable and urgent in today's workforce development. Future studies will look at the importance of teacher presence, working with students from rural communities, specifically looking at how their needs differ from other traditional online students. Additionally, research is needed to promote student engagement in online classes using metrics to measure the presence of engagement. Evidence based driven for ongoing improvement is needed.

\section{REFERENCES}

Bryk, A.S, Gomez, L. M., Grunow, A., \& LeMahieu, P. G. (2016). Learning to Improve: How America's Schools Can Get Better at Getting Better. Cambridge, MA: Harvard Education Press.

Babson Research Group. (2015). 2015 Online report card - Tracking online education in the United States. Retrieved on April 15, 2017 from https://onlinelearningconsortium.org/read/online-report-card-tracking-onlineeducation- united-states-2015

Baptiste, I. (2001). Pedagogical implications of human capital theory. Adult Education Quarterly, 51(3), $184-201$.

Bembenutty, H. (2011). Introduction of learning in postsecondary education. New Directions for Teaching and Learning, 125, 3-8.

Bragg, D. D. (2013). Career and Technical Education: Old Debates, Persistent Challenges in Community Colleges. In Levin, J. S. and Kater, S. T. Ed. Understanding Community Colleges. pp. 187-202. New York: NY: Routledge.

Chai, S., Bagchi-Sen, S.; Goel, R., Rao, H. R., \& Upadhyaya, S. (2006). A Framework for Understanding Minority Students' Cyber Security Career Interests. Proceedings of the 12th Americans Conference on Information System, Acapulco, Mexico.

Chawdhry, A., Paullet, K., \& Benjamin, D. (2011). Comparatively assessing the use of Blackboard versus Desire2Learn: Student Perceptions of the Online Tools. Issues in Information Systems, 12(2). 273-280.

Dembo, M. H. \& Seli, H. (2013). Motivation and Learning Strategies for College Success: A Focus on SelfRegulated Learning, 4th ed., New York and London: Routledge Taylor \& Francis Group. 


\section{Issues in Information Systems}

Volume 19, Issue 4, pp. 1-9, 2018

Douglas, D. M., Paullet, K., \& Chawdhry, A. (2015). Student perspectives of cheating in online classes. Issues in Information Systems, 16(4), 215-223.

Herrera, S., \& Murry, K., (2010). A CLASSIC Approach to Collaboration: Documenting a Multi- State University and Multi-School District Partnership. In Slater, J.J. and Ravid, R., Eds. Collaboration in Education, pp. 161-167. New York, NY: Routledge.

IBM. (2013). Cybersecurity education for the next generation: Advancing a collaborative approach. Retrieved September 16, 2013 from http://www.ibm.com/smarterplanet/us/en/centerforappliedinsights/article/cybersecurity.html.

Karabenick, S.A., \& Dembo, M. H. (2011). Help seeking as a strategic resource. In S. A. Karabenick (Ed.), Strategic help seeking: New Directions for Teaching and Learning, 126, 33-34.

Kemmis, S. \& McTaggart, R. (2005). Participatory Action Research: Communicative Action and the Public Space. In Denzin, N. K. and Lincoln, Y. S., (eds.). The Sage Handbook of Qualitative Research, 3rd ed., pp. 271330. London: Sage Publications.

Maui County Data Book. (2012) Retrieved September 16, 2013, from http:// hisbdc.org/BusinessResearchLibrary/MauiCountyDataBook2012.aspx.

McNiff, J. (2013). Action Research: Principles and Practices, 3rd Ed. New York: NY: Routledge.

Morest, V. S \& Karp, M. M. (2006). Twice the Credit, Half the Time? The Growth of Dual.

Mintrop, R. (2016). Design-Based School Improvement: A Practical Guide for Education Leaders. Cambridge, Massachusetts: Harvard Business Press.

Computing in the Core (2012). Retrieved September 18, 2013, from http://www.computinginthecore.org/factsresources.

Credit at Community Colleges and High School. In Bailey, T. and Morest, V.S., Eds.

Defending the Community College Equity Agenda, pp. 223-245. Baltimore, MD: Johns Hopkins University Press.

Nakama, D.A. (2016). Community Colleges' Outreach Role in Cybersecurity. National Cybersecurity Institute Journal, 3(2), 35-39.

National Center for Women in Technology (2013), from https://www.ncwit.org.

National Initiative for Cybersecurity (NICE). (2012). Retrieved September 23, 2013, from http://csrc.nist.gov/nice/.

Osterman, P. (2012). The Promise, Performance, and Policies of Community Colleges. In Wildavsky, B., Kelly, A.P., and Carey, K., Eds. Reinventing Higher Education: The Promise of Innovation, pp. 129-158. Cambridge, MA: Harvard Education Press.

Penner-Willams, J., Perez, D., Worthen, D. G., Herrera, S., \& Murry, K., 2010). A CLASSIC Approach to Collaboration: Documenting a Multi-State University and Multi-School District Partnership. In Slater, J.J. \& Ravid, R., Eds. Collaboration in Education, pp. 161-167. New York, NY: Routledge.

Sakai. (2018). Sakai Online Learning Management System. Retrieved on April 25, 2018 from https://www.sakaiproject.org/about

Sargut \& Mcgrath (2011). Learning to live with complexity. Harvard Business Review, September, 69-76. 


\section{Issues in Information Systems}

Volume 19, Issue 4, pp. 1-9, 2018

Spence, M. (1973). Job marketing signaling. The Quarterly Journal of Economics, 87(3), 355-374. Retrieved from: http:// www.bcf.usc.edu/ shaddin/cs590fa13/papers/jobmarketsignaling.pdf.

Syed, M. \& Chemers, M.M. (2011). Ethnic Minorities and Women in STEM: Casting a Wide Net to Address a Persistent Social Problem. Journal of Social Issues, 76(3), 435-441.

TestOut. (2017). TestOut: The lessons only experience can teach. Retrieved on April 15, 2017 from http://www.testout.com/

United States Department of Labor, Bureau of Labor Statistics 2011. Retrieved September 16, 2013, from http://www.census.gov/2010census/.

Whitehead, J. (2010). As an educator and educational researcher, how do I improve what I am doing and contribute to educational theories that carry hope for the future of humanity? Inquire in Education, 1(2), Article 2. Retrieved from: http://digitalcommons.nl.edu/ie/vol1/iss2/2. 